\title{
Group Decision Analysis with Interval Type-2 Fuzzy Numbers
}

\section{Galina Ilieva}

University of Plovdiv Paisii Hilendarski, Plovdiv, Bulgaria

Email: galili@uni-plovdiv.bg

\begin{abstract}
This paper presents a group multi-criteria DEMATEL and VIKOR decision analysis method with interval type-2 fuzzy sets. In order to compare normal fuzzy trapezoidal numbers, we convert them into crisp values using graded mean integration representation. By a case study for selection of business intelligence platform, we prove that the proposed combination is a feasible solution that can work with benefits and costs criteria, while also reducing uncertainty in experts' assessments.
\end{abstract}

Keywords: Group decision making, multi-criteria decision analysis, DEMATEL, VIKOR, interval type-2 fuzzy sets, business intelligence.

\section{Introduction}

Continuous and increasing integration of information technology in virtually all areas of human activity as well as rapid growth in analysis of organizations' data require a reliable comparison of many alternatives represented with varying importance. Unfortunately, classic Multi-Criteria Decision Analysis (MCDA) methods have their weaknesses and do not always find an optimal solution to the complex and dynamic real-life problems [11, 19, 21, 23].

One of the drawbacks of traditional models lies in the assumption that criteria are independent and form a hierarchical structure, but in practice that assumption does not always hold. Another disadvantage of conventional MCDA algorithms is that they focus on productivity, while the quality of the resulting ranking or selection remains somewhat neglected. In both cases, the consequences are negative to users relatively good alternatives drop out of the top rankings. However, the combination of DEcision MAking Trial and Evaluation Laboratory (DEMATEL) and VIseKriterijumska Optimizacija i kompromisno Resenje (VIKOR) has the potential to overcome these shortcomings of traditional models and successfully solve complex problems that modern organizations face in their operations. While the first method uncovers mutual relations between criteria, the additive VIKOR method 
aggregates and ranks alternatives according to their distance from the optimal solution.

It is often that decision-makers solve the task of Multiple-Criteria Decision Making (MCDM) in a subjective fashion, relying on intuition, personal opinion and/or experience. Therefore, the relevance of the MCDA problem stems not only from the need of advanced algorithms and information systems for multi-criteria ranking, but also from the necessity to eliminate improper involvement of the human factor. A logical choice to help overcome the problem of subjectivity and imprecision in experts' estimates is the fuzzy sets theory. It is widely used in various areas where statistical information is unreliable or very scarce, such as management, engineering and others. Converting a fuzzy number into an adequate crisp value is one of fuzzy theory's focus points. The creation and analysis of effective methods for type reduction of advanced interval-valued, intuitionistic, hesitant, ordered and others non-crisp sets, is an area of active research today [12, 17, 22]. Interval Type-2 Fuzzy Numbers (IT2 FNs) suitably reflect subjective opinion and present a richer perception of the surrounding world, which is why they are appropriate in making decisions requiring the participation of many experts. Because of their interval membership values and relative simplicity, IT2 FNs are suitable for complex computational studies [25].

The purpose of this work is to develop and apply an IT2 FNs modification of DEMATEL and VIKOR in a hybrid group MCDA model. The rest of the paper is organized as follows: Section 2 introduces DEMATEL, VIKOR, and their modifications. Section 3 describes the implementation steps used in new fuzzy DEMATEL-VIKOR combination and the peculiarities of this new MCDA variation. Section 4 presents a case study illustrating the application of the proposed new hybrid method in selecting Business Intelligence (BI) software. Finally, the results are compared with those obtained when applying other extensions of fuzzy DEMATEL and VIKOR.

\section{Short literature review}

DEMATEL is an analytic algorithm for building a hierarchical model of criteria and it belongs to MCDA methods with pair-wise comparison. This method is suitable for collaborative decision making. For calculating cause and effect relationships between criteria, the method applies matrix calculations and logical (Boolean) operators.

The advantages of DEMATEL include its abilities to:

- evaluate and establish worth and importance using the entire set of factors instead of considering specific parameters only;

- reveal the relationships between criteria in complex problems;

- determine direct and indirect dependencies among the unpredictable attributes [9].

The main disadvantage of the method is that it requires considerable time to provide pair-wise judgments for all combinations when the number of comparisons is large. In case of bounded resources and time, this would seriously hamper evaluators. 
The DEMATEL method can effectively solve complex relationships' issues among given preferences and it is successfully applied in reverse logistics [1], renewable energy resources [2], green production [26], etc. Applying DEMATEL not only improves the quality of the decision to better reflect the importance and the relationship between the criteria, but it also affects positively the productivity and efficiency of the DM method that is used subsequently.

VIKOR is based on an aggregating function that represents closeness to the reference point(s) by using intermediate auxiliary orderings. The ranking index is a summation of all criteria, the relative importance of the criteria, and a balance between total and individual satisfaction. As a result, the method provides a ranking list, where the highest ranked alternative is the closest to the ideal solution.

VIKOR's main advantage is in its ability to detect a compromise solution, which is useful in the presence of competitive offers and conflicting criteria. A specific feature of the method is that it introduces the multi-criteria ranking index based on the particular measure of "closeness" to the "ideal" solution [4, 7]. VIKOR also typically utilizes linear normalization in order to eliminate the units of criteria estimates.

Comprehensive information about the specifics of the VIKOR method and its modern applications can be found in numerous review articles such as [14, 29]. In recent years, a variety of interval-valued fuzzy VIKOR extensions have been proposed [8] as well as hybrid models featuring fuzzy VIKOR [27].

The main challenge in fuzzy MCDA methods is the transition from fuzzy to crisp evaluations. Modifications of fuzzy DEMATEL and VIKOR listed in literature apply various indices that rank and calculate the distance between fuzzy numbers. According to [28], there are three basic fuzzy ordering indices: defuzzification, reference set, and comparing preference relations. Defuzzification is simpler and easier than fuzzy pair-wise comparison on ranking fuzzy numbers. However, defuzzification loses uncertainty of messages. In a reference set method, choosing the base reference set and conducting an adequate measurement by using it as the standard is difficult. Fuzzy pair-wise comparison is complex and difficult, but it preserves fuzziness in messages $[16,18,20]$.

Due to the reasons listed above, the most common technique for ranking in the modern modifications of fuzzy MCDA methods is defuzzification. For example, Lee and Chen convert IT2FN into crisp value through the concept of ranking values [13]. $\mathrm{Hu}$ et al. propose the expected value formula to convert IT2 FN [10]. Ghorabaee et al. develop a new method for fuzzy MCDM based on a new formula for trapezoidal IT2 FN conversion [6].

The current work proposes a defuzzification based on graded mean integration representation [24]. The core of the proposed new MCDA model is the concept of selecting the solution with the shortest distance from the positive-ideal solution (VIKOR part) using criteria importance (DEMATEL part) by considering concepts of IT2 FSs. A specific feature of the proposed hybrid method is the application of the formula for graded mean integration representation to convert IT2 FN into a crisp value. 


\section{Proposed hybrid DEMATEL and VIKOR modification}

Let a MCDM problem have $n$ alternatives $\left(A_{1}, \ldots, A_{n}\right)$ and $m$ decision criteria $\left(C_{1}, \ldots, C_{m}\right)$, and each alternative is assessed according to the criteria. The idea behind the proposed model is that a MCDA procedure combines DEMATEL and VIKOR, as the first method reveals relationships between criteria and calculates their importance, while the second method provides an acceptable compromise solution to the problem of multi-criteria ordering. The block diagram of the proposed hybrid MCDA model is shown in Fig. 1.

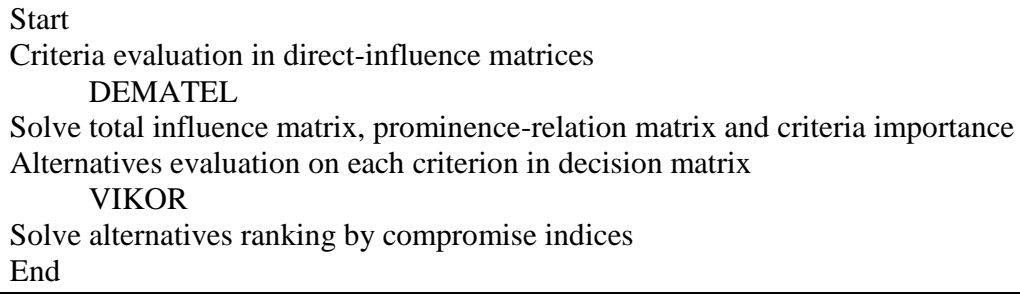

Fig. 1. Evaluation procedure with DEMATEL and VIKOR combination

In the first part of the model, using DEMATEL, by segmenting and analyzing cause and effect factors, key criteria for comparing alternatives are identified. The sequence of actions in the proposed modification of DEMATEL is presented in Fig. 2.

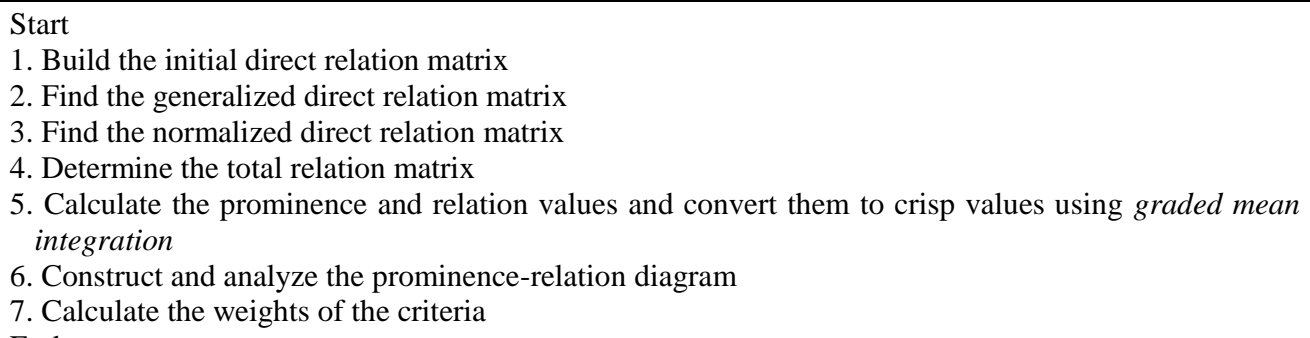

Fig. 2. The new DEMATEL modification flowchart

Here is a detailed description of the new modification of DEMATEL:

Step 1. In the initial direct relation matrix, the $k$-th DM is given IT2 FN score $d_{i j}^{k}$, which takes into consideration the relationship between criteria $i$ and $j$.

Step 2. The generalized direct relation matrix $D$ is calculated in Equation (1) by averaging individual IT2 FN assessments of DMs:

(1) $D_{i j}=\frac{1}{H} \sum_{k=1}^{H} d_{i j}^{k}$, where $i, j=1, \ldots, m, H$ is the total number of DMs and $d_{i j}^{k}=\left(a_{i 1}^{L}, a_{i 2}^{L}, a_{i 3}^{L}, a_{i 4}^{L}, H_{1}\left(\tilde{A}_{i}^{L}\right), H_{2}\left(\tilde{A}_{i}^{L}\right)\right),\left(a_{i 1}^{U}, a_{i 2}^{U}, a_{i 3}^{U}, a_{i 4}^{U}, H_{1}\left(\tilde{A}_{i}^{U}\right), H_{2}\left(\tilde{A}_{i}^{U}\right)\right)$, where $a_{i 1}^{L}, a_{i 2}^{L}, a_{i 3}^{L}, a_{i 4}^{L}$ form LMF, $a_{i 1}^{U}, a_{i 2}^{U}, a_{i 3}^{U}, a_{i 4}^{U}$ are UMF, and $H_{1}\left(\tilde{A}_{i}^{L}\right), H_{2}\left(\tilde{A}_{i}^{L}\right), H_{1}\left(\tilde{A}_{i}^{U}\right), H_{2}\left(\tilde{A}_{i}^{U}\right)$ are heights of LMF and UMF [15]. $D_{i j}$ shows the initial direct influence that a criterion exerts on and receives from other criteria. 
Step 3. The normalized direct relation matrix $P$ is constructed by using the normalized the direct-influence matrix $D$ in the next equations.

$$
\begin{gathered}
P=\frac{D}{s}, \\
s=\max \left\{\max _{1 \leq i<n} \sum_{j=1}^{m} d_{i j}, \max _{1 \leq j<n} \sum_{i=1}^{m} d_{i j}\right\} .
\end{gathered}
$$

Step 4. Once the normalized direct-influence matrix $P$ is obtained, the totalinfluence matrix $T$ for Normalized Relation Matrix (NRM) can be derived through the next quation, in which $I$ denotes the identity matrix:

$$
\begin{gathered}
T=P+P^{2}+P^{3}+\ldots+P^{k}= \\
=P\left(I+P+P^{2}+\ldots+P^{k-1}\right)(I-P)(I-P)^{-1}= \\
=P\left(I-P^{k}\right)(I-P)^{-1}=P(I-P)^{-1},
\end{gathered}
$$

when $k \rightarrow \infty, P^{k}=[0]_{m \times m}$, where $P=\left[p_{i j}\right]_{m \times m}, 0 \leq p_{i j}<1,0<\sum_{j=1}^{m} p_{i j} \leq 1$ and $0<\sum_{i=1}^{m} p_{i j} \leq 1$. If at least one row or column of summation is equal to 1 , but not all, then $\lim _{k \rightarrow \infty} P^{k}=[0]_{m \times m}$.

Step 5. Analyze the results. In this step first we defuzzify the eight matrices $T$ obtained in Step 4 (with crisp elements, respectively $a_{i 1, j}^{L}, a_{i 2, j}^{L}, a_{i 3, j}^{L}, a_{i 4, j}^{L}$, $\left.a_{i 1, j}^{U}, a_{i 2, j}^{U}, a_{i 3, j}^{U}, a_{i 4, j}^{U}, \quad i, j=1,2, \ldots, m\right)$ using the graded mean integration representation from Equation (5) for calculations [24].

(5) $P(A)=\frac{1}{2} \int_{0}^{1} h\left[\left(a_{1}+\left(a_{2}-a_{1}\right) h^{\frac{1}{n}}+\left(a_{4}-\left(a_{4}-a_{3}\right) h^{\frac{1}{n}}\right)\right] d h / \int_{0}^{1} h d h\right.$.

The sum of the rows and the sum of the columns are separately expressed as vector $r=\left(r_{1}, \ldots, r_{i}, \ldots, r_{m}\right)$ and vector $s=\left(s_{1}, \ldots, s_{i}, \ldots, s_{m}\right)^{t}$ by using Equations (6)-(8). For $i, j \in\{1,2, \ldots, m\}$, the horizontal axis vector $r_{i}+s_{i}$ is then built by adding $r_{i}$ to $s_{i}$, which illustrates the importance of the criterion. Similarly, the vertical axis vector $r_{i}-s_{i}$ is constructed, which may separate criteria into a cause group and an affected group. In general, if $r_{i}-s_{i}$ is positive, the criterion is part of the cause group. On the contrary, if $r_{i}-s_{i}$ is negative, the criterion is part of the affected group. Therefore, a causal graph can be achieved by mapping the dataset of $\left(r_{i}+s_{i}, r_{i}-s_{i}\right)$, and it would provide a valuable approach for further decision-making,

$$
\begin{gathered}
T=\left[t_{i j}\right]_{m \times m^{\prime}}, i, j=1,2, \ldots, m, \\
r=\left[\sum_{i=1}^{m} t_{i j}\right]_{m \times 1}=\left[t_{i}\right]_{m \times 1}=\left(r_{1}, \ldots, r_{i}, \ldots, r_{m}\right), \\
s=\left[\sum_{j=1}^{m} t_{i j}\right]_{1 \times m}^{\mathrm{T}}=\left[t_{j}\right]_{m \times 1}^{\mathrm{T}}=\left(s_{1}, \ldots, s_{j}, \ldots, s_{m}\right)^{\mathrm{T}},
\end{gathered}
$$

where vector $r$ and vector $s$ express the sum of the rows and the sum of the columns from the total-influence matrix $T=\left[t_{i j}\right]_{m \times m}$ respectively, and the superscript denotes the transpose [3]. Now we calculate $r_{i}+s_{i}$ and $r_{i}-s_{i}, i=1, \ldots, m$.

Step 6. In this step, we construct a causal diagram and analyze the results obtained. The horizontal axis vector $r_{i}+s_{i}$, titled "prominence", shows the degree of importance that criterion $i$ has in the system. The vertical axis $r_{i}-\mathrm{s}_{i}$, denoted "relation", shows the net effect the criterion $i$ contributed to the system. When $r_{i}-s_{i}$ is positive, the criterion $i$ is a net causer, otherwise the $i$-th criterion is a net receiver.

Step 7. To determine the criteria's importance, we use the next equation: 


$$
W=\left[\frac{\sqrt{\left(r_{i}+s_{i}\right)^{2}+\left(r_{i}-s_{i}\right)^{2}}}{\sum_{i=1}^{n} \sqrt{\left(r_{i}+s_{i}\right)^{2}+\left(r_{i}-s_{i}\right)^{2}}}\right]_{1 \times m} .
$$

The resulting weight coefficients will be used hereinafter in the VIKOR part of the model.

Up until now with the help of DEMATEL, we converted the relations between cause and effect factors into an intelligent structural model of the evaluated criteria. As the assessment is done by fuzzy linguistic variables, we have to incorporate a method for converting IT2 FN into a crisp value. We use graded mean integration representation two times (for UMF and LMF) and find the Euclidean distance between the obtained values.

After determining factors' relative importance in the DEMATEL part, we move on to finding the ranking of compared alternatives using the IT2 FN VIKOR method. Let decision matrix $X=\left(x_{i j}\right)_{n \times m}$ shows all values which are assigned to the alternatives for each criterion. The relative weight of each criterion, found above in the DEMATEL part, is shown as $W=\left(w_{1}, \ldots, w_{m}\right)$.

Fig. 3 presents the step-wise modified procedure for implementing VIKOR. After forming an initial decision matrix, the procedure starts by normalizing the decision matrix. This is followed by building the weighted normalized decision matrix in Step 2, determining the optimal solution in Step 3. In Step 4, for calculating the separation measures for each alternative, we propose using graded mean integration representation (Equation (5)). The procedure ends by computing the set of compromise ranking indices. The given alternatives (or candidates) are ranked according to their descending order.

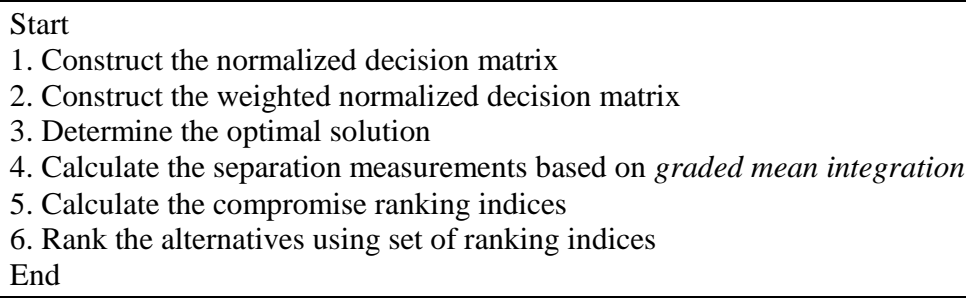

Fig. 3. The new VIKOR modification flowchart

Let us represent the assessment of the effectiveness of criterion $C_{j}$ on alternative $A_{i}$ by $f_{i j}$; the weigth of relative importance of the $j$-th criterion by $w_{j}$; and the highest and lowest assessments of the criterion's effectiveness by $f_{j}^{*}=\max _{j} f_{i j}$ and $f_{j}^{-}=\min _{j} f_{i j}$ for $j=1, \ldots, m$, where $m$ is the number of criteria, that are used to assess each of the given alternatives. The idea behind searching for a compromise solution in the VIKOR method is based on the $L^{p}$ metric, proposed by the method's authors:

$$
L_{i}^{p}=\left\{\sum_{j=1}^{m}\left[w_{j} \frac{\left|f_{j}^{*}-f_{i j}\right|}{\left|f_{j}^{*}-f_{j}^{-}\right|}\right]^{p}\right\}^{1 / p}, 1 \leq p<\infty, i=1, \ldots, n .
$$

The compromise solution is the $i$-th alternative from the evaluated set $\left\{A_{i}\right\}$, for which the value of $L_{i}^{p}$ is at minimum: 


$$
A_{i}=A^{*} \Leftrightarrow i \mid \min _{i} L_{i}^{p}
$$

To formulate the ranking measure, VIKOR also uses $L_{i}^{p=1}$ (as $S_{i}$ in Equation (12)) and $L_{i}^{p=\infty}$ (as $Q_{i}$ in Equation (13)):

$$
\begin{gathered}
S_{i}=L_{i}^{P=1}=\sum_{j=1}^{m}\left[w_{j} \frac{\left|f_{j}^{*}-f_{i j}\right|}{\left|f_{j}^{*}-f_{j}^{-}\right|}\right], \\
Q_{i}=L_{i}^{P=\infty}=\max _{j}\left[w_{j} \frac{\left|f_{j}^{*}-f_{i j}\right|}{\left|f_{j}^{*}-f_{j}^{-}\right|}\right], j=1, \ldots, m .
\end{gathered}
$$

The difference between $f_{j}^{*}-f_{i j}$ is called that alternative's regret; here $\min _{i} S_{i}$ expresses the minimization of the sum of the individual regrets of each alternative (which corresponds each alternative's maximum utility); $\min _{i} Q_{i}$ on the other hand, is the minimization of the maximum individual regret of each alternative (and, correspondingly, determines the minimum regret alternative).

The detailed steps of the VIKOR modification are as follows:

Step 1. Construct the original decision matrix $X=\left(x_{i j}\right)_{n \times m}$.

Step 2. Compute the normalized weight-rating matrix as follows:

$$
F=X_{\text {norm }}=\left(w_{j} x_{i j}\right)_{n \times m}=\left(f_{i j}\right)_{n \times m} .
$$

Step 3. Determine the best $f_{j}^{*}$, and the worst $f_{j}^{-}$values of all criteria, $j=1, \ldots, n$. If the $j$-th function represents a benefit, then $f_{j}^{*}=\max _{j} f_{i j}$ (or setting an aspired level) and $f_{j}^{-}=\min _{j} f_{i j}$ (or setting a tolerable level). Alternatively, if the $j$-th function represents a cost/risk, then $f_{j}^{*}=\min _{j} f_{i j}$ (or setting an aspired level) and $f_{j}^{-}=\max _{j} f_{i j}$ (or setting a tolerable level).

Step 4. Compute the crisp values $S_{i}$ and $Q_{i}$ according to Equations (12) and (13) and IT2 FN graded mean integration conversion formula.

Step 5. Compute the index value $R_{i}, i=1, \ldots, n$, using the formula:

$$
R_{i}=v \frac{S_{i}-S^{*}}{S^{-}-S^{*}}+(1-v) \frac{Q_{i}-Q^{*}}{Q^{-}-Q^{*}},
$$

where $S^{*}=\min _{i} S_{i}$ (or setting the best $S^{*}=0$ ), $S^{-}=\max _{i} S_{i}$ (or setting the worst $S^{-}=1$ ), $Q^{*}=\min _{i} Q_{i}$ (or setting the best $Q^{*}=0$ ), $Q^{-}=\max _{i} Q_{i}$ (or setting the worst $Q^{-}=1$ ), and $0 \leq v \leq 1$, where $v$ is introduced as a weight for the strategy of maximum group utility, whereas $1-v$ is the weight of the individual regret. In other words, when $v>0.5$, this represents a decision-making process that could use the strategy of maximum group utility (i.e., if $v$ is big, group utility is emphasized), or by consensus when $v \approx 0.5$, or with veto when $v<0.5$.

Step 6. Rank the alternatives, sorting them by the value of $S_{i}, Q_{i}$ and $R_{i}$, $i=1, \ldots, n$, in a decreasing order. Propose as a compromise the alternative $A^{I}$ which is ranked first by the measure $\min \left\{R_{i} \mid i=1,2, \ldots, n\right\}$ if the following two conditions are satisfied:

Condition 1. Acceptable advantage in decision making: $R\left(A^{I I}\right)-R\left(A^{I}\right) \geq$ $1 /(n-1)$, where $A^{I I}$ is the alternative with second position in the ranking list by $R$; $n$ is the number of alternatives. 
Condition 2. Acceptable stability in decision making: Alternative $A^{I}$ must also be the best ranked by $S_{i}$ or/and $Q_{i}, i=1, \ldots, n$.

If one of the conditions is not satisfied, then a set of compromise solutions is proposed, which consists of:

- Alternatives $A^{I}$ and $A^{I I}$ if only Condition 2 is not satisfied.

- Alternatives $A^{I}, A^{I I}, \ldots, A^{(M)}$ if condition 1 is not satisfied. $A^{(M)}$ is determined by the relation $R\left(A^{(M)}\right)-R\left(A^{I}\right)<1 /(n-1)$ for maximum $\mathrm{M}$ (the positions of these alternatives are close).

The compromise solution is determined by the compromise-ranking method; the obtained solution could be accepted by the decision makers because it provides maximum group utility of the majority (represented by $\min S$, Equation (12)), and minimum individual regret of the opponent (represented by min $Q$, Equation (13)). The VIKOR algorithm can also determine the weight stability intervals for the obtained compromise solution with the input weights given by the experts or calculated by a pair-wise method.

In this section, we combined IT2 FN DEMATEL and VIKOR to build a decision matrix, weights, and rankings by the experts' opinions. Using the proposed method, in the next section we find the BI platforms' ranking.

\section{BI platform selection example using the proposed DEMATEL- VIKOR modification}

Selecting proper BI System (BIS) in organizations is a complex task that requires a comparison of a growing number of platforms with dozens of features under incomplete and inaccurate experts' evaluations. Unfortunately, there are no accepted models for BIS evaluation and ordering in the literature. After a review on BI specifications, we prefer an assessment model, based on the next seven criteria [12]:

$C 1$ - Groupware;

$C 2$ - Simulation;

C3 - Modeling;

C4 - Data Mining and Intelligent Techniques;

C5 - Interoperability;

C6 - Reporting Tools;

C7 - Data Warehouse.

We aim to rank the top four BI and analytics products found on the Bulgarian BI market. We chose three experts, an IT manager, a business analyst and an IT lecturer, with experience working with BI, to create the initial decision matrices and weighted coefficients' comparison.

To express the dependences between criteria, the nine grade linguistic scale is proposed and correspondence between linguistic variables and symmetric fuzzy trapezoid IT2 FNs is shown in Table 1. The fuzzy numbers that have been used are depicted graphically in Fig. 4. 
Table 1. Linguistic terms and their corresponding trapezoidal IT2FNs

\begin{tabular}{|l|l|}
\hline \multicolumn{1}{|c|}{ Linguistic terms } & \multicolumn{1}{c|}{ Trapezoidal IT2 FNs } \\
\hline No influence (No) & $((0,0,0.05,0.15),(0,0,0.035,0.125))$ \\
\hline Very Low (VL) & $((0,0.1,0.15,0.25),(0.025,0.115,0.135,0.225))$ \\
\hline Low (L) & $((0.125,0.225,0.275,0.375),(0.15,0.24,0.26,0.35))$ \\
\hline Medium Low (ML) & $((0.25,0.35,0.4,0.5),(0.275,0.365,0.385,0.475))$ \\
\hline Medium (M) & $((0.375,0.475,0.525,0.625),(0.4,0.49,0.51,0.6))$ \\
\hline Medium High (MH) & $((0.5,0.6,0.65,0.75),(0.525,0.615,0.635,0.725))$ \\
\hline High (H) & $((0.625,0.725,0.775,0.875),(0.65,0.74,0.76,0.85))$ \\
\hline Very High (VH) & $((0.75,0.85,0.9,1),(0.775,0.865,0.885,0.975))$ \\
\hline Absolutely High (AH) & $((0.875,0.975,1,1),(0.9,0.99,1,1))$ \\
\hline
\end{tabular}

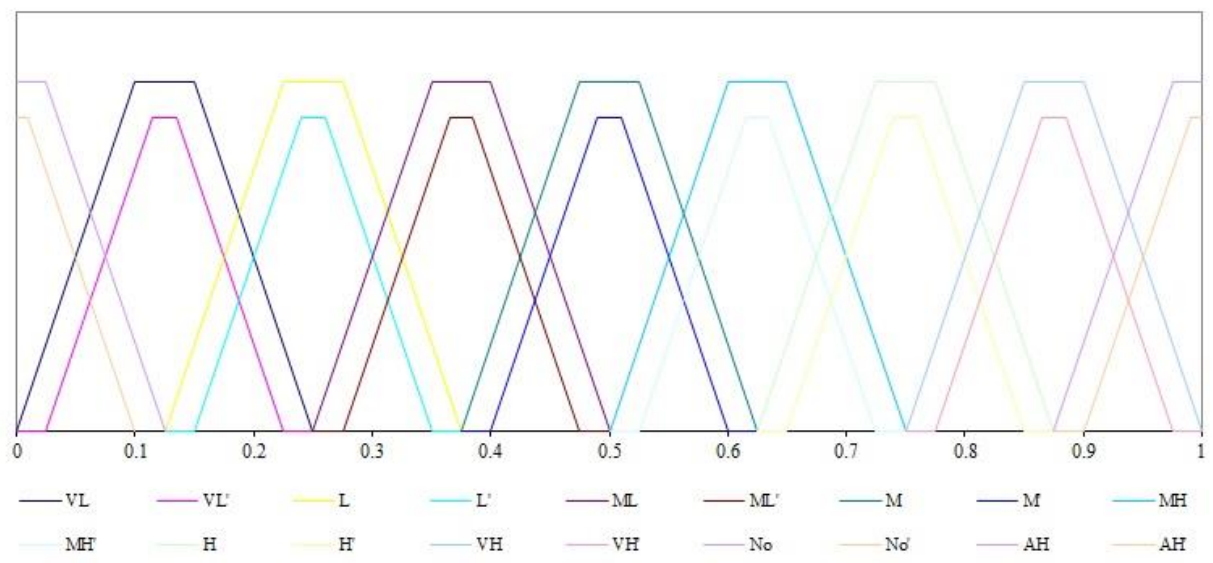

Fig. 4. Membership functions of the linguistic terms

The initial experts' direct relation matrices (Fig. 2, Step 1) can be found in Table 2, Table 3 and Table 4.

Table 2. Initial direct relation matrix $\left[d_{i j}{ }^{1}\right]$

\begin{tabular}{|l|r|r|r|r|r|r|r|}
\hline Criteria & \multicolumn{1}{|c|}{$C 1$} & $C 2$ & $C 3$ & $C 4$ & $C 5$ & $C 6$ & $C 7$ \\
\hline$C 1$ & 1 & No & $\mathrm{VL}$ & No & ML & ML & VL \\
\hline$C 2$ & $\mathrm{AH}$ & 1 & $\mathrm{~L}$ & $\mathrm{~L}$ & $\mathrm{ML}$ & $\mathrm{M}$ & $\mathrm{H}$ \\
\hline$C 3$ & $\mathrm{VH}$ & $\mathrm{H}$ & 1 & $\mathrm{ML}$ & $\mathrm{L}$ & $\mathrm{M}$ & $\mathrm{H}$ \\
\hline$C 4$ & $\mathrm{AH}$ & $\mathrm{H}$ & $\mathrm{MH}$ & 1 & $\mathrm{MH}$ & $\mathrm{L}$ & $\mathrm{MH}$ \\
\hline$C 5$ & $\mathrm{MH}$ & $\mathrm{MH}$ & $\mathrm{H}$ & $\mathrm{ML}$ & 1 & $\mathrm{~L}$ & $\mathrm{H}$ \\
\hline$C 6$ & $\mathrm{VH}$ & $\mathrm{M}$ & $\mathrm{M}$ & $\mathrm{H}$ & $\mathrm{H}$ & 1 & $\mathrm{H}$ \\
\hline$C 7$ & $\mathrm{VH}$ & $\mathrm{L}$ & $\mathrm{L}$ & $\mathrm{ML}$ & $\mathrm{L}$ & $\mathrm{L}$ & 1 \\
\hline
\end{tabular}

Table 3. Initial direct relation matrix $\left[d_{i j}{ }^{2}\right]$

\begin{tabular}{|l|c|c|c|c|c|c|c|}
\hline Criteria & $C 1$ & $C 2$ & $C 3$ & $C 4$ & $C 5$ & $C 6$ & $C 7$ \\
\hline$C 1$ & 1 & $\mathrm{VL}$ & $\mathrm{L}$ & No & $\mathrm{ML}$ & No & No \\
\hline$C 2$ & $\mathrm{VH}$ & 1 & $\mathrm{ML}$ & $\mathrm{VL}$ & $\mathrm{M}$ & $\mathrm{VH}$ & $\mathrm{H}$ \\
\hline$C 3$ & $\mathrm{H}$ & $\mathrm{MH}$ & 1 & $\mathrm{VL}$ & $\mathrm{M}$ & $\mathrm{VH}$ & $\mathrm{MH}$ \\
\hline$C 4$ & $\mathrm{AH}$ & $\mathrm{VH}$ & $\mathrm{VH}$ & 1 & $\mathrm{H}$ & $\mathrm{M}$ & $\mathrm{AH}$ \\
\hline$C 5$ & $\mathrm{MH}$ & $\mathrm{M}$ & $\mathrm{M}$ & $\mathrm{L}$ & 1 & $\mathrm{~L}$ & $\mathrm{M}$ \\
\hline$C 6$ & $\mathrm{AH}$ & $\mathrm{VL}$ & $\mathrm{VL}$ & $\mathrm{M}$ & $\mathrm{H}$ & 1 & $\mathrm{~L}$ \\
\hline$C 7$ & $\mathrm{AH}$ & $\mathrm{L}$ & $\mathrm{ML}$ & No & $\mathrm{M}$ & $\mathrm{H}$ & 1 \\
\hline
\end{tabular}


Table 4. Initial direct relation matrix $\left[d_{i j}{ }^{3}\right]$

\begin{tabular}{|l|r|r|r|r|r|r|r|}
\hline Criteria & \multicolumn{1}{|c|}{$C 1$} & \multicolumn{1}{c}{$C 2$} & \multicolumn{1}{c|}{$C 3$} & \multicolumn{1}{c|}{$C 4$} & $C 5$ & $C 6$ & $C 7$ \\
\hline$C 1$ & 1 & $\mathrm{~L}$ & $\mathrm{ML}$ & $\mathrm{L}$ & $\mathrm{ML}$ & $\mathrm{VL}$ & $\mathrm{L}$ \\
\hline$C 2$ & $\mathrm{H}$ & 1 & $\mathrm{M}$ & $\mathrm{ML}$ & $\mathrm{M}$ & $\mathrm{H}$ & $\mathrm{MH}$ \\
\hline$C 3$ & $\mathrm{MH}$ & $\mathrm{M}$ & 1 & $\mathrm{ML}$ & $\mathrm{M}$ & $\mathrm{ML}$ & $\mathrm{L}$ \\
\hline$C 4$ & $\mathrm{H}$ & $\mathrm{MH}$ & $\mathrm{MH}$ & 1 & $\mathrm{MH}$ & $\mathrm{M}$ & $\mathrm{AH}$ \\
\hline$C 5$ & $\mathrm{MH}$ & $\mathrm{M}$ & $\mathrm{M}$ & $\mathrm{ML}$ & 1 & $\mathrm{~L}$ & $\mathrm{ML}$ \\
\hline$C 6$ & $\mathrm{VH}$ & $\mathrm{L}$ & $\mathrm{MH}$ & $\mathrm{M}$ & $\mathrm{H}$ & 1 & $\mathrm{H}$ \\
\hline$C 7$ & $\mathrm{H}$ & $\mathrm{ML}$ & $\mathrm{H}$ & $\mathrm{No}$ & $\mathrm{MH}$ & $\mathrm{L}$ & 1 \\
\hline
\end{tabular}

In case of non-beneficial criteria, the reciprocal value of respective fuzzy numbers is used. The result from Step 5 of DEMATEL is shown in Table 5, while calculated cause-effect values are displayed in Table 6.

Table 5. Defuzzified total influence matrix $T_{i j}$

\begin{tabular}{|c|l|l|l|l|l|l|l|l|}
\hline Criteria & $C 1$ & $C 2$ & $C 3$ & $C 4$ & $C 5$ & $C 6$ & $C 7$ & $R$ \\
\hline$C 1$ & 0 & 0.005 & 0.009 & 0.004 & 0.011 & 0.004 & 0.005 & 0.038 \\
\hline$C 2$ & 0.032 & 0 & 0.014 & 0.010 & 0.015 & 0.025 & 0.026 & 0.122 \\
\hline$C 3$ & 0.028 & 0.023 & 0 & 0.011 & 0.016 & 0.021 & 0.020 & 0.119 \\
\hline$C 4$ & 0.034 & 0.027 & 0.026 & 0 & 0.025 & 0.016 & 0.031 & 0.160 \\
\hline$C 5$ & 0.024 & 0.020 & 0.021 & 0.012 & 0 & 0.010 & 0.020 & 0.107 \\
\hline$C 6$ & 0.034 & 0.012 & 0.016 & 0.021 & 0.027 & 0 & 0.022 & 0.131 \\
\hline$C 7$ & 0.032 & 0.013 & 0.017 & 0.006 & 0.017 & 0.015 & 0 & 0.099 \\
\hline$D$ & 0.183 & 0.099 & 0.104 & 0.064 & 0.110 & 0.092 & 0.125 & 0 \\
\hline
\end{tabular}

Table 6. Results from modified DEMATEL - values of $R_{i}+D_{i}, R_{i}-D_{i}$

\begin{tabular}{|c|r|r|r|r|}
\hline Criteria & $R$ & \multicolumn{1}{c|}{$D$} & $R+D$ & \multicolumn{1}{c|}{$R-D$} \\
\hline$C 1$ & 0.038 & 0.183 & 0.222 & -0.145 \\
\hline$C 2$ & 0.122 & 0.099 & 0.221 & 0.022 \\
\hline$C 3$ & 0.119 & 0.104 & 0.223 & 0.016 \\
\hline$C 4$ & 0.160 & 0.064 & 0.224 & 0.096 \\
\hline$C 5$ & 0.107 & 0.11 & 0.217 & -0.003 \\
\hline$C 6$ & 0.131 & 0.092 & 0.223 & 0.040 \\
\hline$C 7$ & 0.099 & 0.125 & 0.224 & -0.026 \\
\hline
\end{tabular}

The obtained results are very similar to those arrived at via two alternative defuzzification methods: expected value method $E(V)[10]$ and DTraT method (Table 7).

Table 7. $R_{i}+D_{i}, R_{i}-D_{i}$ values via alternative defuzzification formulas

\begin{tabular}{|c|r|r|r|r|}
\hline \multirow{2}{*}{ Criteria } & \multicolumn{2}{|c|}{$E(V)$} & \multicolumn{2}{c|}{$D$ TraT } \\
\cline { 2 - 5 } & $R_{i}+D_{i}$ & \multicolumn{1}{c|}{$R_{i}-D_{i}$} & $R_{i}+D_{i}$ & \multicolumn{1}{c|}{$R_{i}-D_{i}$} \\
\hline$C 1$ & 0.168 & -0.110 & 0.178 & -0.115 \\
\hline$C 2$ & 0.168 & 0.017 & 0.177 & 0.018 \\
\hline$C 3$ & 0.169 & 0.012 & 0.179 & 0.012 \\
\hline$C 4$ & 0.170 & 0.072 & 0.179 & 0.076 \\
\hline$C 5$ & 0.165 & -0.002 & 0.174 & -0.002 \\
\hline$C 6$ & 0.169 & 0.030 & 0.179 & 0.032 \\
\hline$C 7$ & 0.170 & -0.019 & 0.179 & -0.020 \\
\hline
\end{tabular}


Weight coefficients calculated according to Equation (9) are identical for all three methods: $w_{1}=0.163, w_{2}=0.137, w_{3}=0.138, w_{4}=0.150, w_{5}=0.134, w_{6}=0.140$, and $w_{7}=0.139$.

As is shown in Fig. 5, DEMATEL builds a structural model of cause and effect relationships among given peer-wise compared criteria. According to the total influential prominence $R_{i}+D_{i}$, Data warehouse $(C 7)$ demonstrates the highest total influential prominence among other factors, while Interoperability $(C 5)$ is the factor with the weakest total influential prominence. According to the influential relation $R_{i}-D_{i}$, Data mining and intelligent techniques $(C 4)$ and Reporting tools $(C 6)$ have the highest degrees of impact relationship and directly affect other factors. Otherwise, Groupware $(C 1)$ is more vulnerable to influence than other preferences.

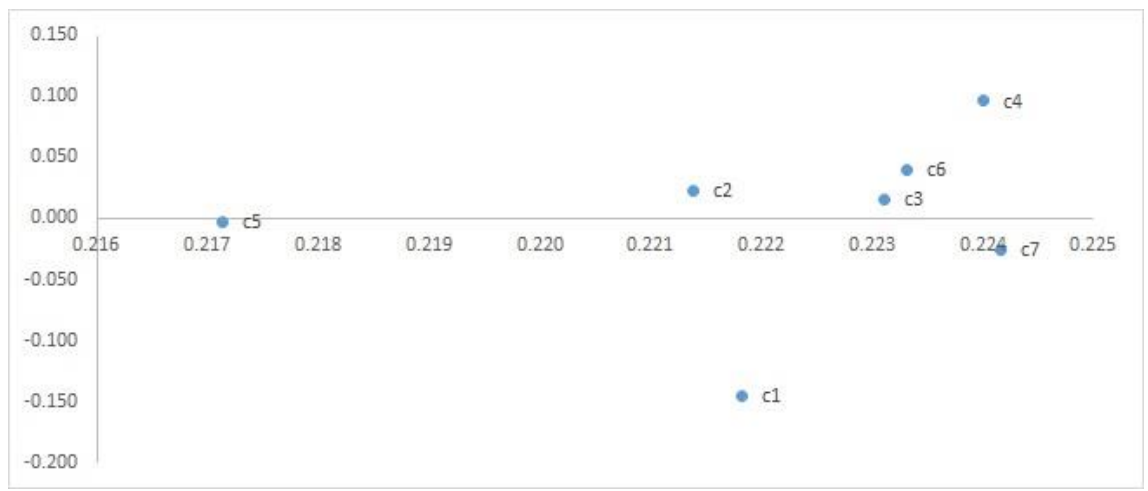

Fig. 5. Causal diagram $R_{i}+D_{i}, R_{i}-D_{i}$

DEMATEL divides the criteria set into three groups. The first one, cause group (above the $x$-axis), includes Simulation, Modeling, Data mining and intelligent techniques, and Reporting tools members. The second one is effect group with two criteria - Groupware and Data Warehouse. The last group consists of only one criterion - Interoperability. In this case, it is only logical that the four criteria Simulation, Modeling, Data mining and intelligent techniques, and Reporting tools belong to the cause group. It is so, as it is to be expected that BI platforms users find it important to discover hidden relationships and forecast, model and simulate business processes, as well as to provide offline and online reporting instruments. With queries and reports for making tactical decisions, as well as dashboards, alerts, etc., decision makers can control how business activities are performed in real time.

It is a fact that Groupware, Interoperability, and Data Warehouse generate negative $R_{i}-D_{i}$ values. In the case of Data Warehouse, we believe that it is more logical this criterion to be referred to the group of cause criteria. This statement is a consequence of the fact that data warehouses are an essential component of the architecture of modern business intelligent systems. As the focal point of the center for preparation of data and analytic environment, data warehouses accelerate business analysis and support decisions regarding tactical and strategic objectives of organizations. In this case, our recommendation to experts is to examine and analyze in more detail the proposed multiple preferences before proceeding with their assessment, taking into account the causal relationships between criteria revealed by 
DEMATEL. The results shown in the causal diagram correspond well with the last Gartner BI and Analytics report's idea of bimodal IT, where Mode 1 represents traditional IT delivery and Mode 2 represents the type of agile delivery usually employed by digital native companies [5].

In order to rank the four BI products with VIKOR, we employ the decision matrix and weighted coefficients from Table 8 [12].

Table 8. Decision matrix and weighted coefficients

\begin{tabular}{|c|c|c|c|c|c|c|c|}
\hline Alternative & $C 1$ & $C 2$ & $C 3$ & $C 4$ & $C 5$ & $C 6$ & $C 7$ \\
\hline$A 1$ & $\mathrm{~L}$ & $\mathrm{AH}$ & $\mathrm{VH}$ & $\mathrm{VH}$ & $\mathrm{H}$ & $\mathrm{AH}$ & $\mathrm{VH}$ \\
\hline$A 2$ & $\mathrm{~L}$ & $\mathrm{M}$ & $\mathrm{L}$ & $\mathrm{L}$ & $\mathrm{VL}$ & $\mathrm{AH}$ & $\mathrm{VH}$ \\
\hline$A 3$ & $\mathrm{M}$ & $\mathrm{M}$ & $\mathrm{L}$ & $\mathrm{H}$ & $\mathrm{L}$ & $\mathrm{M}$ & $\mathrm{H}$ \\
\hline$A 4$ & $\mathrm{H}$ & $\mathrm{H}$ & $\mathrm{L}$ & $\mathrm{AH}$ & $\mathrm{H}$ & $\mathrm{H}$ & $\mathrm{L}$ \\
\hline$W$ & $\mathrm{H}$ & $\mathrm{M}$ & $\mathrm{L}$ & $\mathrm{VH}$ & $\mathrm{M}$ & $\mathrm{VH}$ & $\mathrm{AH}$ \\
\hline
\end{tabular}

Table 9 contains the indices $S_{i}$ (Equation (12)) and $Q_{i}$ (Equation (13)).

Table 9. Defuzzified normalized distances to the positive optimal solution, $S_{i}$, and $Q_{i}$

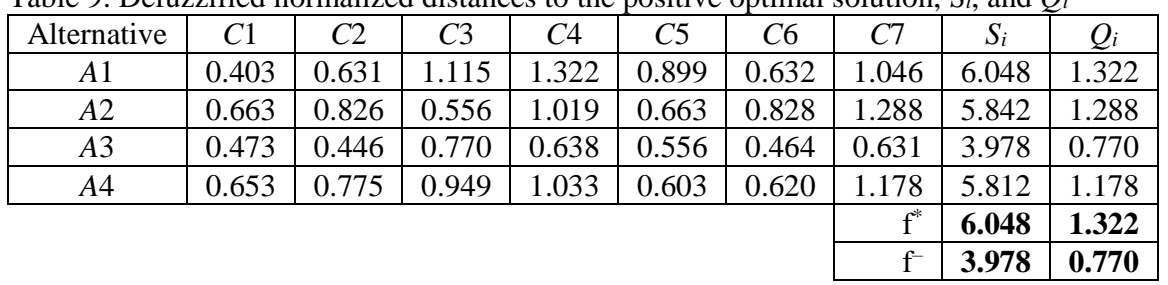

Index $R_{i}$ (Equation (14)) is shown in Table 10 with $v=0.5,0.3$, and 0.7 .

Table 10. Index $R_{i}$ values for three different $v$

\begin{tabular}{|c|r|r|r|c|r|c|}
\hline Alternative & $R_{i}(0.5)$ & Ranking & $R_{i}(0.3)$ & Ranking & $R_{i}(0.7)$ & Ranking \\
\hline$A 1$ & 0.000 & {$[1]$} & 0.000 & {$[1]$} & 0.000 & {$[1]$} \\
\hline$A 2$ & 0.081 & {$[2]$} & 0.073 & {$[2]$} & 0.088 & {$[2]$} \\
\hline$A 3$ & 1.000 & {$[4]$} & 1.000 & {$[4]$} & 1.000 & {$[4]$} \\
\hline$A 4$ & 0.188 & {$[3]$} & 0.217 & {$[3]$} & 0.158 & {$[3]$} \\
\hline
\end{tabular}

We check the condition for presence of acceptable advantage (VIKOR Step 6, Condition 1). Since $\quad R\left(A^{I I}\right)-R\left(A^{I}\right) \approx 0.08<\frac{1}{n-1}=\frac{1}{4-1}=\frac{1}{3}=0$. (33), Condition 1 is not met. Condition 2 is not met as well (the best is not best according to $S_{i}$ and/or $Q_{i}$ ). Therefore, we proceed to check the existence of $M$ such that $R\left(A^{(M)}\right)-R\left(A^{I}\right)<\frac{1}{n-1}=0$. (33). The equation holds for $M=3$, which means that the first three alternatives in the ranking are all acceptable.

When solving the same problem using IT2FN modification of TOPSIS and $D$ TraT formula as described in [12] we obtained ranking $A_{1}>A_{4}>A_{2}>A_{3}$. All three methods place Alternative 1 at the top, followed by Alternative 2 and Alternative 4. In this case, although VIKOR is unable to yield leaders in the rankings, it arrives at the same compromise solutions as BIS, which are preferred by both alternative fuzzy methods. This proves that the proposed modification of VIKOR is functional and is able to find acceptable solutions to multi-criteria tasks. 
The proposed fuzzy DEMATEL-VIKOR combination can reveal cause-effect relationships between preferences and can successfully deal with inexact expert evaluation in case of BI selection based on both beneficial and non-beneficial criteria. In addition to that, visualization of cause-effect relationships via influential network relationship map is helpful to BIS companies for planning systematic improvements of their products.

\section{Conclusions}

The feasibility and effectiveness of the proposed DEMATEL and VIKOR combination are illustrated by a numerical example. All BI platforms rankings in the example derived by three different approaches (the new modification, fuzzy TOPSIS extension and DTraT TOPSIS) are found to be very similar. The new method does not require a complicated computation procedure and is therefore beneficial to decision analysis. The disadvantage of this method is its dependence on fuzzy numbers' shapes. In the future, we plan to develop a more general hybrid model, applicable to arbitrary type-2 fuzzy numbers as well as to combine it with other multiattribute decision making techniques.

\section{References}

1. Bouzon, M., K. Govindan, C. Rodriguez. Evaluating Barriers for Reverse Logistics Implementation under a Multiple Stakeholders' Perspective Analysis Using Grey Decision Making Approach. Resources. - Conservation and Recycling, 2017, Science Direct (in Press).

2. В ü y ü k ö z k a n, G., S. G ü l e r y ü z. An Integrated DEMATEL-ANP Approach for Renewable Energy Resources Selection in Turkey. - Production Economics. Vol. 182, 2016, pp. 435-448.

3. Che n, Y. C., Li e n, H. P. Li e n, G. H. Tzeng. Measures and Evaluation for Environment Watershed Plans Using a Novel Hybrid MCDM Model. Expert Systems with Applications, Vol. 37, Issue 2, 2010, pp. 926-938.

4. Fir o u zabadi, S., S. M e hri zi. ERP Software Quality Assessment Using Fuzzy VIKOR. Uncertain Supply Chain Management. Vol. 3, 2015, No 2, pp. 189-196.

5. G a r t n e r. Magic Quadrant for Business Intelligence and Analytics Platforms. Gartner, Inc., 2016. $68 \mathrm{p}$.

6. Ghor ab a e e, M. K., M. A miri, J. S. S ad aghi ani, E. K. Z a vad ska s. Multi-Criteria Project Selection Using an Extended VIKOR Method with Interval Type-2 Fuzzy Sets. Information Technologies and Decision Making, Vol. 14, 2015, Issue 05, pp. 993-1016.

7. G ö r e n e r, A. ERP Software Selection Using a Combined ANP and VIKOR Approach. - Havacilik Ve Uzay Teknolojileri Dergisi. Vol. 5, 2011, No 1, pp. 97-110.

8. Gu l, M., E. Celik, N. Aydin, A. T. Gumus, A. F. Guneri, A State of the Art Literature Review of VIKOR and its Fuzzy Extensions on Applications. - Applied Soft Computing, Vol. 46, 2016, pp. 60-89.

9. H o r i, S., Y. S h i m i z u. Designing Methods of Human Interface for Supervisory Control Systems. - Control Engineering Practice, Vol. 7, 1999, No 11, pp. 1413-1419.

10. Hu, J., Y. Zhang, X. Chen, Y. Li u. Multi-Criteria Decision Making Method Based on Possibility Degree of Interval Type-2 Fuzzy Number. - Knowledge-Based Systems, Vol. 43, 2013, pp. 21-29.

11. I li e va, G. A Fuzzy Approach for Bidding Strategy Selection. - Cybernetics and Information Technologies, Vol. 12, 2012, No 1, pp. 61-69.

12. I 1 i e va, G. TOPSIS Modification with Interval Type-2 Fuzzy Numbers. - Cybernetics and Information Technologies, Vol. 16, 2016, No 2, pp. 60-68. 
13. L e e, L.-W., S.-M. C h e n. Fuzzy Interpolative Reasoning Using Interval Type-2 Fuzzy Sets. - In: N. T. Nguyen, L. Borzemski, A. Grzech, M. Ali, Eds. New Frontiers in Applied Artificial Intelligence, Springer, 2008, pp. 92-101.

14. Mardani, A., A. Ju s oh, E. K. Zavadskas. Fuzzy Multiple Criteria Decision-Making Techniques and Applications - Two Decades Review from 1994 to 2014. - Expert Systems with Applications, Vol. 42, 2015, Issue 8, pp. 4126-4148.

15. Mende 1, J. M., R. I. John. Interval Type-2 Fuzzy Logic Systems Made Simple. - IEEE Transactions on Fuzzy Systems, Vol. 14, 2006, No 6, pp. 808-821.

16. Peneva, V., I. Popchev. Fuzzy Ordering on the Basis of Multi-Criteria Aggregation. Cybernetics and Systems, Vol. 29, 1998, Issue 6, pp. 613-623.

17. Peneva, V., I. Pop chev. Fuzzy Logic Operators in Decision-Making. - Cybernetics and Systems, Vol. 30, 1999, Issue 8, pp. 725-745.

18. P e n e v a, V., I. P o p c h e v. Aggregation of Fuzzy Relations Using Weighting Function. - Compt. Rend. Acad. bulg. Sci., Vol. 60, 2007, No 10, pp. 1047-1052.

19. P e n e v a V., I. P o p c h e v. Fuzzy Criteria Importance with Weighting Functions. - Comp. Rend. Acad. bulg. Sci. Vol. 61, 2008, No 3, pp. 293-300.

20. P e n e va, V., I. P o p che v. Models for Fuzzy Multicriteria Decision Making Based on Fuzzy Relations. - Compt. Rend. Acad. bulg. Sci., Vol. 62, 2009, No 5, pp. 551-558.

21. P e n e va, V., I. P o p c h e v. Fuzzy Multi-Criteria Decision Making Algorithms. - Compt. Rend. Acad. bulg. Sci., Vol. 63, 2010, No 7, pp. 979-992.

22. Po p chev, I., V. Pen eva. An Algorithm for Comparison of Fuzzy Sets. - Fuzzy Sets and Systems. Vol. 60, 1993, Issue 1, pp. 59-65.

23. Radeva, I. Multi-Criteria Models for Cluster Design. - Cybernetics and Information Technologies, Vol. 13, 2013, No 1, pp. 18-33.

24. R e z v a n i, S. Representation of Trapezoidal Fuzzy Numbers with Shape Function. - Annals of Fuzzy Mathematics and Informatics, Vol. 8, 2014, No 1, pp. 89-112.

25. R u n k 1 e r, T., S. C o u p l a n d, R. J o h n. Interval Type-2 Fuzzy Decision Making. - Approximate Reasoning, Vol. 80, 2017, pp. 217-224.

26. S h a o, J., M. T a i s ch, M Orte ga-Mier. A Grey-DEcision-MAking Trial and Evaluation Laboratory (DEMATEL) Analysis on the Barriers between Environmentally Friendly Products and Consumers: Practitioners' Viewpoints on the European Automobile Industry. - Cleaner Production. Vol. 112, 2016, pp. 3185-3194.

27. Tadić, S., S. Z e čević, M. Krstić. A Novel Hybrid MCDM Model Based on Fuzzy DEMATEL, Fuzzy ANP and Fuzzy VIKOR for City Logistics Concept Selection. - Expert Systems with Applications, Vol. 41, 2014, Issue 18, pp. 8112-8128.

28. W a n g, X., E. K e r r e. On the Classification and the Dependencies of the Ordering Methods. - In: D. Ruan, Ed. Fuzzy Logic Foundations and Industrial Applications. Kluwer Academic Publishers, Dordrecht, 1996, pp. 73-90.

29. Y a zdani, M., F. R. Graem l. VIKOR and Its Applications: A State-of-the-Art Survey. Strategic Decision Sciences, Vol. 5, 2014, Issue 2, pp. 56-83. 